\title{
Dispersity and Size of Silica Particles Constructing Thick Films Prepared by Electrophoretic Sol-Gel Deposition
}

\author{
Hideki NISHIMORI, Masahiro TATSUMISAGO and Tsutomu MINAMI \\ Department of Applied Materials Science, College of Engineering, Osaka Prefecture University, 1-1, Gakuen-cho, Sakai-shi, Osaka \\ ゾル・ゲル電気泳動電着により作製したシリカ厚膜粒子の分散性及び粒径 \\ 西森秀樹・辰巳砂昌弘・南 努 \\ 大阪府立大学工学部機能物質科学科, 593 堺市学園町 1-1
}

593

[Received February 9, 1995; Accepted April 1, 1995]

\begin{abstract}
Thick silica films prepared on a stainless steel sheet by the electrophoretic sol-gel deposition in the presence of sodium dodecyl sulfate (SDS) as a surfactant were found to be an agglomerate of fine silica particles. The size and the dispersity of the silica particles on the sheet were dependent on the concentrations of both tetraethoxysilane (TEOS) and SDS. The particle size increased with an increase in the content of SDS. Monodispersed particles were obtained at relatively low concentrations of TEOS, whereas bimodal particles were deposited at higher concentrations of TEOS.
\end{abstract}

Key-words : Electrophoretic sol-gel deposition, Thick film, Silica, Sodium dodecyl sulfate (SDS), Particle size, Dispersity

1. Introduction

The electrophoretic sol-gel deposition starting from metal alkoxides has been developed as one of the useful procedures to prepare thick and dense films of metal oxides. ${ }^{1)}$ Recently we have reported that thick silica films with a thickness of about $20 \mu \mathrm{m}$ were formed on a stainless steel sheet by the electrophoretic sol-gel deposition by adding sodium dodecyl sulfate (SDS) ${ }^{2)}$ in the preparation of silica particles similar to the process by Stöber, Fink and Bohn (SFB process). .3) The films formed were found to be an agglomerate of monodispersed particles (0.3-0.6 $\mu \mathrm{m}$ in diameter). It is important to elucidate how the properties of resultant particles like size and dispersity are influenced by the composition of the sols like concentrations of metal alkoxides and SDS in order to obtain excellent thick films by the electrophoretic deposition.

The SFB process and the emulsion process starting from metal alkoxides are well known as typical sol-gel procedures to prepare spherical oxide particles. ${ }^{4)}$ Surfactants or polymers have been widely used for preparation of the particles in such procedures. Ogihara et al. reported the preparation of monodispersed metal oxide $\left(\mathrm{ZrO}_{2}, \mathrm{TiO}_{2}, \mathrm{Al}_{2} \mathrm{O}_{3}\right.$, $\mathrm{Nb}_{2} \mathrm{O}_{5}$ and $\mathrm{Ta}_{2} \mathrm{O}_{5}$ ) particles using the emulsion process in the presence of hydroxypropyl-cellulose
(HPC).5) Jean and Ring prepared monodispersed $\mathrm{TiO}_{2}$ particles by adding HPC in the SFB process. $\left.{ }^{6}\right)$ Preparation of silica particles by use of surfactants as emulsifiers were also widely reported ${ }^{7), 8)}$ as well as the surface modification of silica particles in the presence of surfactants by the emulsion process. ${ }^{9)}$ However, no studies have been done on the influence of the concentration of ionic surfactants like SDS on the properties of silica particles like size and dispersity in the SFB process.

In the present study, we have prepared thick films on a stainless steel sheet by using a variety of concentrations of SDS and tetraethoxysilane (TEOS). This paper reports the concentration dependence of SDS and TEOS on the size and the dispersity of the silica particles which form the thick films on the stainless steel sheet.

\section{Experimental procedures}

Deionized, distilled water, distilled ethanol (EtOH) and reagent grade chemicals of TEOS, ammonium hydroxide $\left(\mathrm{NH}_{4} \mathrm{OH}\right)$ and SDS (Wako Pure Chemical Industries, Ltd., Osaka, Japan) were used as starting materials. The $\mathrm{pH}$ of water was adjusted by adding $\mathrm{NH}_{4} \mathrm{OH}$.

The SDS dissolved in $\mathrm{H}_{2} \mathrm{O}(\mathrm{pH}=11.7)$ and TEOS were diluted separately with the same amount of EtOH. The two solutions were mixed and stirred at room temperature for $1 \mathrm{~h}$. The mole ratios of TEOS/ $\mathrm{H}_{2} \mathrm{O} /$ EtOH were $x / 10 / 10$, where $0.2 \leq x \leq 0.75$. The concentration of SDS added was $0.05-0.2$ mass\% against the total weight of the sols $(70 \mathrm{~g})$. Particles prepared were electrophoretically deposited on the stainless steel sheet (SUS304) in the manner reported previously. ${ }^{2)}$ The silica particles forming the thick films on the stainless steel sheet were observed by a scanning electron microscope (SEM) (JEOL : JSM-5300). The mean particle size and the size distribution were determined by measuring diameter of 100 particles for each of the samples.

\section{Results and discussion}

Figure 1 shows SEM photographs of the particles forming the thick films of about $5-20 \mu \mathrm{m}$ in thick- 

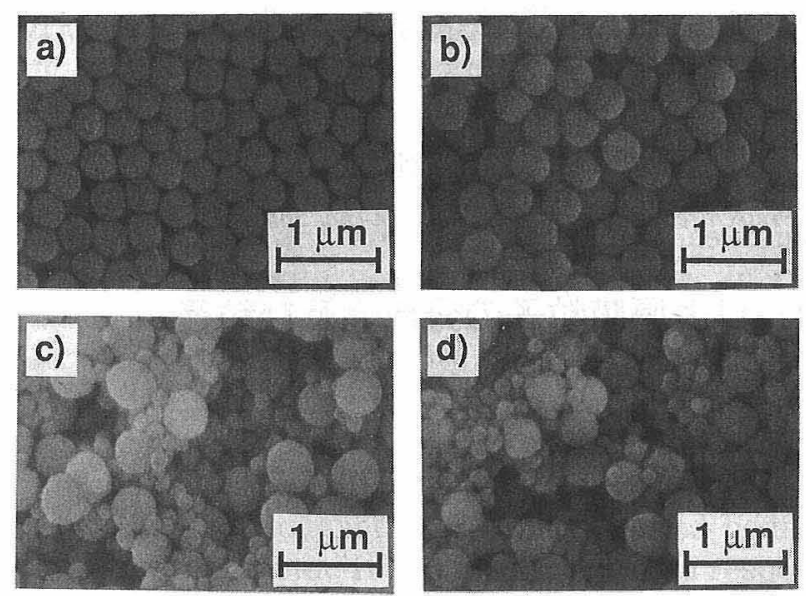

Fig. 1. SEM photographs of silica particles deposited on stainless steel sheets by varying the mole ratios of TEOS, $x$, against 10 mol of $\mathrm{H}_{2} \mathrm{O}$ and EtOH. a) : $\left.\left.\left.x=0.2, \mathrm{~b}\right): x=0.3, \mathrm{c}\right): x=0.4, \mathrm{~d}\right)$ : $x=0.5$. Content of SDS added was fixed to be 0.1 mass $\%$.

ness deposited on the stainless steel sheets by electrophoresis where $10-30 \mathrm{~V}$ was applied for $10 \mathrm{~min}$. These particles were prepared from solutions with different mole ratios of TEOS, (a) $x=0.2$, (b) $x=0.3$, (c) $x=0.4$ and (d) $x=0.5$, where the amount of SDS added was fixed to be 0.1 mass $\%$. In the case of small $x$ values $(\leq 0.3)$, deposited particles are monodispersed. However, when the values are larger than 0.4 , the particles become apparently polydispersed. Finally at $x=0.75$, particles were agglomerated and sedimented in the sol prepared.

Figure 2 shows the size distributions of the silica particles shown in Fig. 1. The compositions of the sols are the same as in Fig. 1. When the mole ratios of TEOS, $x$, are 0.2 and 0.3 , narrow size distributions are obtained (geometrical standard deviations, $\sigma_{\mathrm{g}}$, being 1.05 and 1.08 , respectively) and the mean particle sizes, $d$, are almost the same in both compositions $(0.34-0.35 \mu \mathrm{m})$. On the other hand, smaller particles which have about $0.15 \mu \mathrm{m}$ in diameter are also observed as well as larger particles (ca. $0.4 \mu \mathrm{m}$ ) at $x=0.4$ and 0.5 . The bimodal particles (ca. 0.4 and $0.15 \mu \mathrm{m}$ ) were observed at all the part of the films when $x$ was 0.4 and 0.5 .

Dispersity of the particles prepared would relate to the length of nucleation period. Since the nucleation of silica particles following hydrolysis of TEOS completes in very short time under a low concentration of TEOS $(x \leq 0.3)$, the particles grow uniform1y. In case of higher concentrations of TEOS $(x \geq 0.4)$, since the nucleation period is rather long, the nucleation and the particle growth take place concurrently. Since the particle size distributions were not continuous but bimodal, the longer nucleation at $x=0.4$ and 0.5 may be divided into two periods, i.e., the first period: initial rapid nucleation (corresponding to rapid nucleation of monodispersed particles) and the second period: slow nucleation arising with particle growth. The smaller particles at $x=0.4$ and

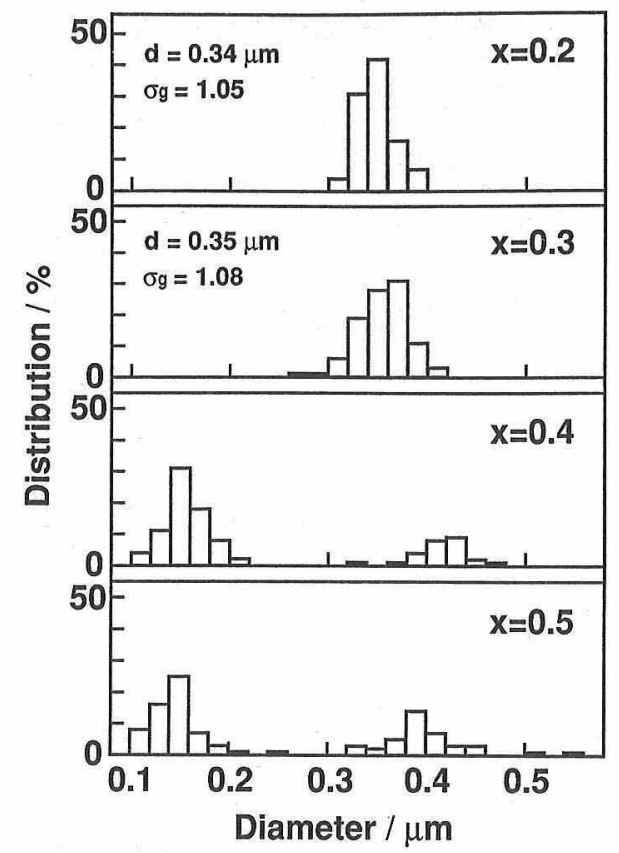

Fig. 2. Particle size distributions of silica, SEM of which are shown in Fig. 1.

0.5 must be caused by the latter nucleation. The nucleation of the larger particles of bimodal distributions at $x=0.4$ and 0.5 and the monodispersed particles at $x=0.2$ and 0.3 takes place at the similar period of the reaction (the initial nucleation) because the larger particles at $x=0.4$ and $0.5(d \approx 0.40$ $\mu \mathrm{m})$ have almost the same size as the particles at $x=0.2$ and $0.3(d \approx 0.35 \mu \mathrm{m})$.

The addition of SDS probably induced the particle growth by the coalescence of the particles because double spherical particles of a submicron order in diameter were observed during the earlier reaction period (up to about $30 \mathrm{~min}$ ) of the sols. The particles nucleated at the first period would chiefly grew by the coalescence to finally yield larger particles (ca. $0.4 \mu \mathrm{m}$ ). The smaller particles generated in the second nucleation period would grow without coalescence because the coalescence period was already completed. The bimodal size distributions were obtained by the difference of growth mechanism between the larger particles and the smaller particles.

Figure 3 shows the size distributions of the silica particles electrophoretically deposited, where the mole ratio of TEOS, $x$, was fixed to be 0.2 and the contents of SDS were changed from 0.05 to 0.2 mass \%. The particles at any concentration of SDS added have narrow size distributions $\left(\sigma_{\mathrm{g}}\right.$ ranging from 1.04 to 1.07$)$. The mean particle diameter is increased from 0.28 to $0.59 \mu \mathrm{m}$ with an increase in the concentration of SDS. The coalescence period may be increased with an increase in the SDS content. The double spherical particles caused by the coalescence gradually changed into spherical particles. Finally monodispersed spheres were obtained by stirring for $1 \mathrm{~h}$. 


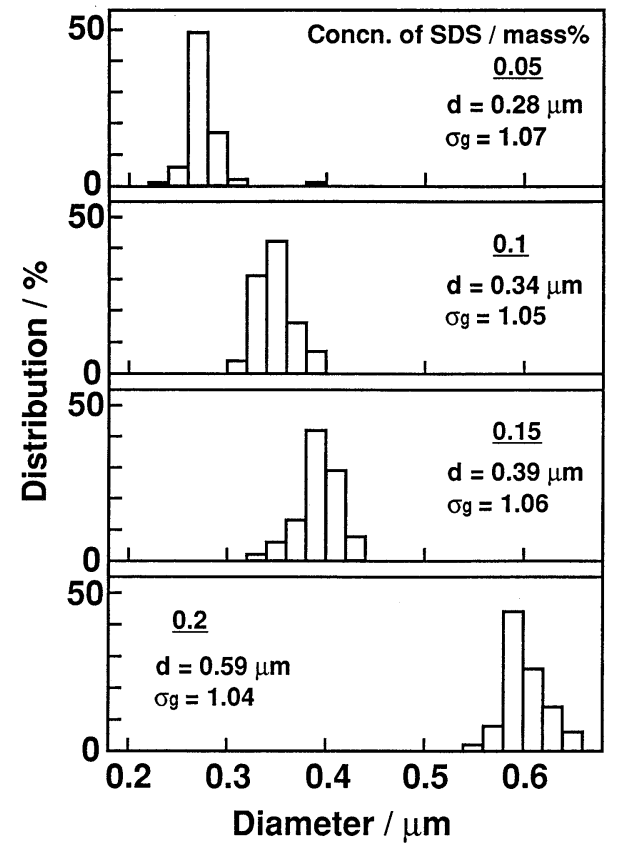

Fig. 3. Particle size distributions of silica deposited on stainless steel sheets with different amounts of SDS added. Mole ratio of TEOS, $x$, was fixed to be 0.2 .

When $x$ was 0.3 , the particle size was also increased with an increase in the concentration of SDS. Detailed mechanism of growth of monodispersed silica particles in the presence of
SDS is now under study and will be published elsewhere.

\section{Conclusions}

Monodispersed silica particles were prepared in the presence of 0.1 mass\% SDS when the mole ratio of TEOS, $x$, against $10 \mathrm{~mol}$ of $\mathrm{H}_{2} \mathrm{O}$ and $\mathrm{EtOH}$ was smaller than 0.3. On the other hand, polydispersed particles with bimodal size distributions were obtained at $x=0.4$ and 0.5 . As the concentration of SDS increased, the particle size became larger with maintaining the small geometrical standard deviation when $x$ were 0.2 and 0.3 .

\section{References}

1) K. Kishida, M. Tatsumisago and T. Minami, J. Ceram. Soc. Japan, 102, 336-40 (1994).

2) H. Nishimori, M. Tatsumisago and T. Minami, J. Ceram. Soc. Japan, 103, 78-80 (1995).

3) W. Stöber, A. Fink and E. Bohn, J. Colloid Interface Sci., 26, 62-69 (1968).

4) G. L. Messing and W. T. Minehan, J. Ceram. Soc. Japan, 99, 1036-46 (1991).

5) T. Ogihara, T. Yanagawa, N. Ogata and K. Yoshida, J. Ceram. Soc. Japan, 101, 315-20 (1993).

6) J. H. Jean and T. A. Ring, Am. Ceram. Soc. Bull., 65, 157477 (1986).

7) H. Yamashita, M. Demiya, H. Mori and T. Maekawa, J. Ceram. Soc. Japan, 100, 1444-47 (1992).

8) P. Espiard, J. E. Mark and A. Guyot, Polym. Bull., 24, 17379 (1990).

9) P. Espiard, A. Revillon, A. Guyot and J. E. Mark, ACS Symp. Ser., 492 (Polym. Latexes), 387-404 (1992). 